\title{
Women's autonomy and social support and their associations with infant and young child feeding and nutritional status: community-based survey in rural Nicaragua
}

\author{
Shirin Ziaei ${ }^{1, *}$, Mariela Contreras ${ }^{1}$, Elmer Zelaya Blandón ${ }^{2}$, Lars-Åke Persson ${ }^{1}$, \\ Anders Hjern ${ }^{3}$ and Eva-Charlotte Ekström ${ }^{1}$ \\ 'Department of Women's and Children's Health, International Maternal and Child Health Unit (IMCH), University \\ Hospital, SE-751 85, Uppsala University, Uppsala, Sweden: ${ }^{2}$ Asociación para el Desarrollo Económico y Social de \\ El Espino (APRODESE), Chinandega, Nicaragua: ${ }^{3}$ Centre for Health Equity Studies, Karolinska Institutet/Stockholm \\ University, Stockholm, Sweden
}

Submitted 20 February 2014: Final revision received 29 September 2014: Accepted 1 0ctober 2014: First published online 20 November 2014

\begin{abstract}
Objective: To evaluate the associations of women's autonomy and social support with infant and young child feeding practices (including consumption of highly processed snacks and sugar-sweetened beverages) and nutritional status in rural Nicaragua.

Design: Cross-sectional study. Feeding practices and children's nutritional status were evaluated according to the WHO guidelines complemented with information on highly processed snacks and sugar-sweetened beverages. Women's autonomy was assessed by a seventeen-item questionnaire covering dimensions of financial independence, household-, child-, reproductive and health-related decision making and freedom of movement. Women's social support was determined using the Duke-UNC Functional Social Support Questionnaire. The scores attained were categorized into tertiles.

Setting: Los Cuatro Santos area, rural Nicaragua.

Subjects: A total of 1371 children 0-35 months of age.

Results: Children of women with the lowest autonomy were more likely to be exclusively breast-fed and continue to be breast-fed, while children of women with middle level of autonomy had better complementary feeding practices. Children of women with the lowest social support were more likely to consume highly processed snacks and/or sugar-sweetened beverages but also be taller. Conclusions: While lower levels of autonomy and social support were independently associated with some favourable feeding and nutrition outcomes, this may not indicate a causal relationship but rather that these factors reflect other matters of importance for child care.
\end{abstract}

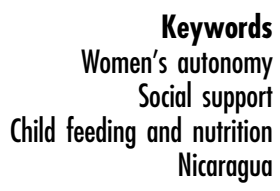

Keywords

Social support Nicaragua
In spite of global improvements in health, child undernutrition remains a major public health problem and is responsible for $45 \%$ of deaths in children under the age of 5 years ${ }^{(1)}$. The significance of care as an underlying factor for child growth and development has been highlighted in the UNICEF conceptual framework ${ }^{(2)}$. The care concept encompasses behaviours of immediate importance for child health, nutrition and development, such as feeding practices, food preparation and storage, hygienic practices, psychosocial stimulation, care for the child during illnesses and care for the woman. In the majority of societies women are the primary caregivers of children. In order to provide effective care they require resources including education, physical and mental health, autonomy, adequate time and social support ${ }^{(2)}$. While the effects of some of these resources - such as education - on child health and development have been extensively evaluated, women's autonomy and social support have received less attention. Autonomy provides women with the opportunity to access and control resources and to use these resources in response to the food and health-care needs of their children. Children of women with lower autonomy have been shown to be at a higher risk of mortality ${ }^{(3,4)}$, underimmunization $^{(5)}$ and morbidity from acute respiratory infections ${ }^{(6)}$. Besides autonomy, adequate social support may increase the amount and quality of care provided by reducing women's workload, stress and/or lack of resources $^{(7)}$. It has been shown that children of women 
with low social support are at a higher risk of mortality ${ }^{(8)}$, life-threatening injuries and illnesses ${ }^{(9)}$ and impaired general health ${ }^{(10)}$. Research evaluating the effects of women's autonomy and social support on children's nutrition is limited and conflicting results have been reported. For instance, greater women's autonomy has been associated with better child nutritional status in India ${ }^{(11,12)}$ and in Jordan ${ }^{(13)}$ among children under 3 years of age. By contrast, in Kenya, no such association was found among children less than 3 years of age, but higher women's autonomy was associated with better nutritional status in 3-10-year-old children ${ }^{(14)}$. In a study conducted by Smith et al., higher women's autonomy was associated with shorter duration of breast-feeding in the three regions of South Asia, sub-Saharan Africa and Latin America $^{(15)}$, while in India a positive association between women's financial autonomy and breast-feeding practices has been observed ${ }^{(12)}$.

Additionally, greater women's social support has been linked to better child nutritional status in children below the age of 2 years, as reported from cross-sectional studies in Vietnam ${ }^{(9)}$ and Brazil ${ }^{(16)}$. In a case-control study in Brazil, women's lack of economic support during adverse events was associated with a higher risk of malnutrition in 12-23-month-old children of low-income families but no such association was found in children of higher-income families ${ }^{(17)}$. These findings suggest that the contribution of both women's autonomy and social support to child nutrition depend on the specific context and the age group in focus.

In Nicaragua, a male dominance tradition has resulted in power inequality and lower women's autonomy in the household ${ }^{(18)}$. Despite economic growth in recent years, the country is still struggling with a high prevalence of poverty, particularly in rural areas ${ }^{(19)}$. While progress towards achieving some of the Millennium Development Goals such as reducing mortality in infants and children younger than 5 years of age seems to be well on track ${ }^{(20)}$, chronic undernutrition remains one of Nicaragua's greatest challenges. Seventeen per cent of children under 5 years of age are stunted ${ }^{(21)}$ and $10 \%$ are reportedly anaemic ${ }^{(22)}$. The country is also going through the nutrition transition with an overweight prevalence of $55 \%$ among adults, of whom $22 \%$ are obese ${ }^{(23)}$.

Although infant and young child feeding practices have been acknowledged as some of the most important aspects of child care and a determinant of child nutrition, limited research has focused on the role of women's autonomy and social support in relation to feeding practices. Understanding the social and contextual factors associated with optimal feeding and nutrition is crucial for ensuring effective nutrition interventions. The present study aims to evaluate the associations of women's autonomy and social support with infant and young child feeding practices (including consumption of highly processed (HP) snacks and sugar-sweetened beverages (SSB)) and nutritional status of 0-35-month-old children in rural Nicaragua.

\section{Methods}

\section{Study setting and population}

The study was conducted in the four municipalities of Santo Tomás del Nance, San Juan de Cinco Pinos, San Pedro del Norte and San Francisco del Norte in northwestern Nicaragua. The area is collectively called 'Los Cuatro Santos' and has about 25000 inhabitants. Most of the population is engaged in small-scale subsistence farming activities and other income-generating opportunities are scarce. There is a high level of unemployment in the area and mothers are mainly involved in household activities and child care with no stable source of income. While breast-feeding is common among the children under 2 years (60\%), exclusive breast-feeding is low (34\%) within the first 6 months of life. Besides, infant and young child feeding practices are poor especially in terms of meal frequency and dietary diversity ${ }^{(24)}$. In 2003, a Health and Demographic Surveillance System (HDSS) covering the whole population was established in the area by a local non-governmental organization called Asociación para el Desarrollo Económico y Social El Espino (APRODESE). So far three rounds of data collection have occurred. From June to November 2009, a group of trained local interviewers visited all households in the HDSS area and collected data on sociodemographic conditions and household food insecurity. All identified households with at least one child below 3 years of age were revisited by a second group of trained interviewers, at which time data were collected on women's autonomy and social support, as well as infant and young child feeding practices and consumption of HP snacks and SSB, and anthropometric measurements were performed.

\section{Data}

Explanatory variables: women's autonomy and social support

We constructed a seventeen-item questionnaire to assess women's autonomy. Five of the seventeen questions were adapted from the Demographic and Health Survey women's questionnaire ${ }^{(25)}$. Twelve other questions were constructed based on review of previous studies and modified by adding questions measuring women's autonomy in relation to child health and nutrition. The final questionnaire measured different dimensions of women's autonomy including financial independence, household-, child-, reproductive and health-related decision making as well as freedom of movement. Women were able to choose between five options ranging from $1=$ 'cannot decide at all' to $5=$ 'decide on my own' for questions such as 'How much can you decide to make large household purchases?' The Cronbach's $\alpha$ for the instrument was 0.91, indicating good internal consistency.

Women's social support was measured by a fifteen-item instrument adapted from the Duke-UNC Functional Social 
Support Questionnaire ${ }^{(26)}$. The questionnaire measured different dimensions of social support including confidant (having someone to share and discuss important matters in life), affective (being shown love and caring) and instrumental (such as having help with money during an emergency) support. Except for the first question, the five response options ranged from $1=$ 'much less than I would like' to $5=$ 'as much as I like' for questions such as 'Do you have people who care what happens to you?' Women's answers to the first question, 'How many friends and relatives do you have?', ranged from $1=$ 'none' to $5=$ 'more than four relatives and friends'. The Spanish version of the questionnaire has been validated in relation to child nutritional status in Latin American settings ${ }^{(27)}$. The Cronbach's $\alpha$ value of the instrument was 0.70 in our sample, suggesting acceptable internal consistency.

A continuous score was created for each one of the instruments by summing up women's responses to the individual questionnaire items. For both instruments the total scores were further categorized into tertiles (lowest, middle and highest) of autonomy and social support, given that factor analysis did not yield distinct subgroup separation.

\section{Outcomes}

A $24 \mathrm{~h}$ FFQ was developed to assess infant and young child feeding practices in accordance with the WHO recommended key indicators ${ }^{(28-30)}$. The questionnaire consisted of seventy food items and eleven beverages, with the food items organized into seven groups as suggested by the WHO guidelines ${ }^{(29,30)}$. The women were asked how many times children had consumed any of the listed items during the day and night prior to the day of the interview. The dietary instrument also included questions about the women's breast-feeding practices as well as the number of times children usually ate per day. To capture additional aspects of feeding of relevance for a society undergoing a nutrition transition, information on consumption of HP snacks and SSB was included by adding six items of apparent high consumption in the study area: soft drinks, sweetened powdered fruit drinks, cookies, candies, chocolates and salty crispy snacks.

In line with the WHO recommended guidelines ${ }^{(29,30)}$ the following feeding indicators were developed and used in the present study.

1. Exclusive breast-feeding: the proportion of infants 0-5 months of age who received only breast milk during the previous day.

2. Continued breast-feeding: the proportion of children 12-15 months of age who received breast milk during the previous day.

3. Minimum dietary diversity: the proportion of children 6-23 months of age who received food from four or more food groups during the previous day. The following seven food groups have been used for tabulation of this indicator: grains, roots and tubers; legumes and nuts; dairy products; flesh foods; eggs; vitamin A-rich fruits and vegetables; other fruits and vegetables.

4. Minimum meal frequency: the proportion of breast-fed and non-breast-fed children 6-23 months of age who received solid, semi-solid or soft foods the minimum number of times or more. Minimum is defined as two times for breast-fed infant aged 6-8 months, three times for breast-fed children aged 9-23 months and four times for non-breast-fed children during the previous day.

5. Minimum acceptable diet: the proportion of breast-fed children 6-23 months of age who had at least the minimum diet diversity and minimum meal frequency during the previous day, and the proportion of nonbreast-fed children 6-23 months of age who received at least two milk feedings and had at least minimum dietary diversity not including milk feeds and the minimum meal frequency during the previous day.

For children older than 24 months, we applied the guidelines for 12-23-month-old children. All feeding indicators were expressed as binary variables $(0 / 1)$ in the statistical models, where 0 represented meeting and 1 represented not meeting the indicator criteria. Considering the fact that HP snacks and SSB are generally accepted as being unhealthy, in particular for young children, we developed a binary indicator representing whether HP snacks and/or SSB were given (1) or not given (0) to the child.

Children's weight (to the nearest $0 \cdot 1 \mathrm{~kg}$ ) and height/length (to the nearest $0 \cdot 1 \mathrm{~cm}$ ) were measured with Tanita digital scales and locally produced wooden boards, respectively. The interviewers were trained in anthropometric measurement techniques and accuracy and precision of their measurements were assessed through standardization sessions. The child anthropometric status outcomes including length/ height-for-age $Z$-score (HAZ), weight-for-height $Z$-score (WHZ), weight-for-age $Z$-score (WAZ) and BMI-for-age $Z$-score (BAZ) were calculated based on the WHO child growth standards ${ }^{(31)}$. HAZ reflects long-term nutritional status and captures evidence of chronic undernutrition, while WHZ is a marker of current nutritional status and sensitive to recent events such as illnesses and food shortage. WAZ is a composite index representing overall nutritional status of the children and BAZ is an index used to capture relative adiposity among children ${ }^{(32)}$. Because of the differences in foremost feeding but also other care needs, we decided to evaluate anthropometric characteristics of the children in two different age strata: below 6 months of age and 6 months and above.

\section{Covariates}

Based on previous research on factors associated with infant and young child feeding practices ${ }^{(33)}$ as well as determinants of child nutritional status in the context of Nicaragua ${ }^{(34)}$, the following indicators were selected as 
potential confounders: municipality, housing quality, food insecurity, women's education, women's age (years), child age (months), child sex and number of children under 5 years of age in the household. Housing quality was calculated using information on the quality of household construction, toilet facilities and sources of water and electricity. A housing quality score was created that ranged from 5 to 15 with the higher score indicating better-quality housing. The index was further divided into tertiles: lowest (5-10), middle (11-12) and highest (13-15). Women's education was classified into lowest ( $<5$ years), middle (5-9 years) and highest ( $>9$ years)

We measured household food insecurity using the Household Food Insecurity Access Scale (HFIAS). The scale consists of nine questions measuring three domains of food insecurity: (i) 'anxiety and uncertainty about the household food supply'; (ii) 'insufficient quality'; and (iii) 'insufficient food intake and its physical consequences, ${ }^{\text {(35) }}$. The scores ranged from 0 to 27 , with a higher score reflecting a higher level of food insecurity. The scale showed high internal consistency in our sample with Cronbach's $\alpha=0.86$. Households were further categorized into lowest (HFIAS score $=0-7$ ), middle (HFIAS score $=8-11$ ) and highest (HFIAS score $=13-27$ ) tertiles of food insecurity.

All of the questionnaires were pilot tested on twenty women in a nearby community with a setting similar to the study area. The pilot testing permitted modifications in the questionnaires such as clarification of phrasing questions and inclusion of missing food items. Prior to and after the pilot testing, the local interviewers underwent several day-long training sessions that included discussion of the concepts of the questions and pseudo interviews. The interviewers were also provided with a manual to be used in the field if needed. All data collection was closely supervised by one of the co-authors (M.C.) who was present in the field.

\section{Statistical analyses}

Descriptive characteristics of women and children are presented as frequencies and percentages. Women's scores on autonomy and social support questionnaires are presented as means and standard deviations. Descriptive statistics of infant and young child feeding practices and consumption of HP snacks and SSB (as categorical variables) are presented as percentages and 95\% confidence intervals according to women's autonomy and social support categories. Normality of child anthropometric data was evaluated and established by visual examination of histograms and Q-Q plots. Descriptive statistics of child nutritional status (as continuous variables) are presented as means and standard deviations for the total sample of children and according to women's autonomy and social support tertiles. We used the $\chi^{2}$ test to compare proportions and ANOVA followed by the Bonferroni post hoc test to compare means and examine factors associated with infant and young child feeding, HP snacks and/or SSB consumption and nutritional status. Finally, we used the general linear model for continuous outcomes and logistic regression for binary outcomes to estimate associations with the main explanatory variables. To facilitate comparisons of our results with results from a series of papers on a similar topic $^{(33)}$, we defined main outcome as negative ('not meeting recommended feeding behaviour') and coded the statistical analyses according to the convention that an odds below 1 is a favourable and an odds above 1 is an unfavourable outcome.

The results in the study are presented in three models. A first unadjusted model was followed by a second model adjusting for factors considered as potential confounders including municipality, housing quality, food insecurity, women's education, women's age (years) and child age (months). In order to evaluate the independent effects of social support and autonomy, a third model was tested where these two factors were both included in addition to the previously mentioned potential confounding factors. Child sex and number of children under 5 years of age in the household were also considered as potential confounders; however, since they were not significantly associated with any of the measured outcomes, they were not included in the final models. The regression diagnostic procedure showed no evidence of multicollinearity (variance inflation factor $<1.172$ and tolerance $>0.853$ ) in the evaluated statistical models. Statistical analyses were performed using the statistical software package IBM SPSS Statistics version 20 and OpenEpi version $3 \cdot 01^{(36)}$.

\section{Results}

Of the 1500 eligible households with children under 3 years of age that were identified by the first group of trained interviewers, 1371 households were revisited and included in the study (Fig. 1). The main reasons for missing data were that the children had not been registered during the first round of household visits or were not found during the second round despite three repeated home visits. Children who had passed the age of eligibility or had questionnaires with missing information were also excluded from the final sample. Table 1 presents household, women's and individual characteristics of the 1371 children aged 0-35 months. The majority of households had a latrine or toilet and access to electricity, while $22 \%$ had access to tap water. Most of the households had earth or soil as the main flooring material and adobe/brick or wood as the main wall material. The majority of the women were housewives and about two-thirds had more than 5 years of schooling. About $20 \%$ of the children were stunted while $9 \%$ were overweight.

The descriptive statistics of women's autonomy and social support scores are presented in Table 2 . The mean score for women's autonomy was 69.3 (SD 9.5; range 34-85). Among women, $72 \%$ decided on their own about the type 


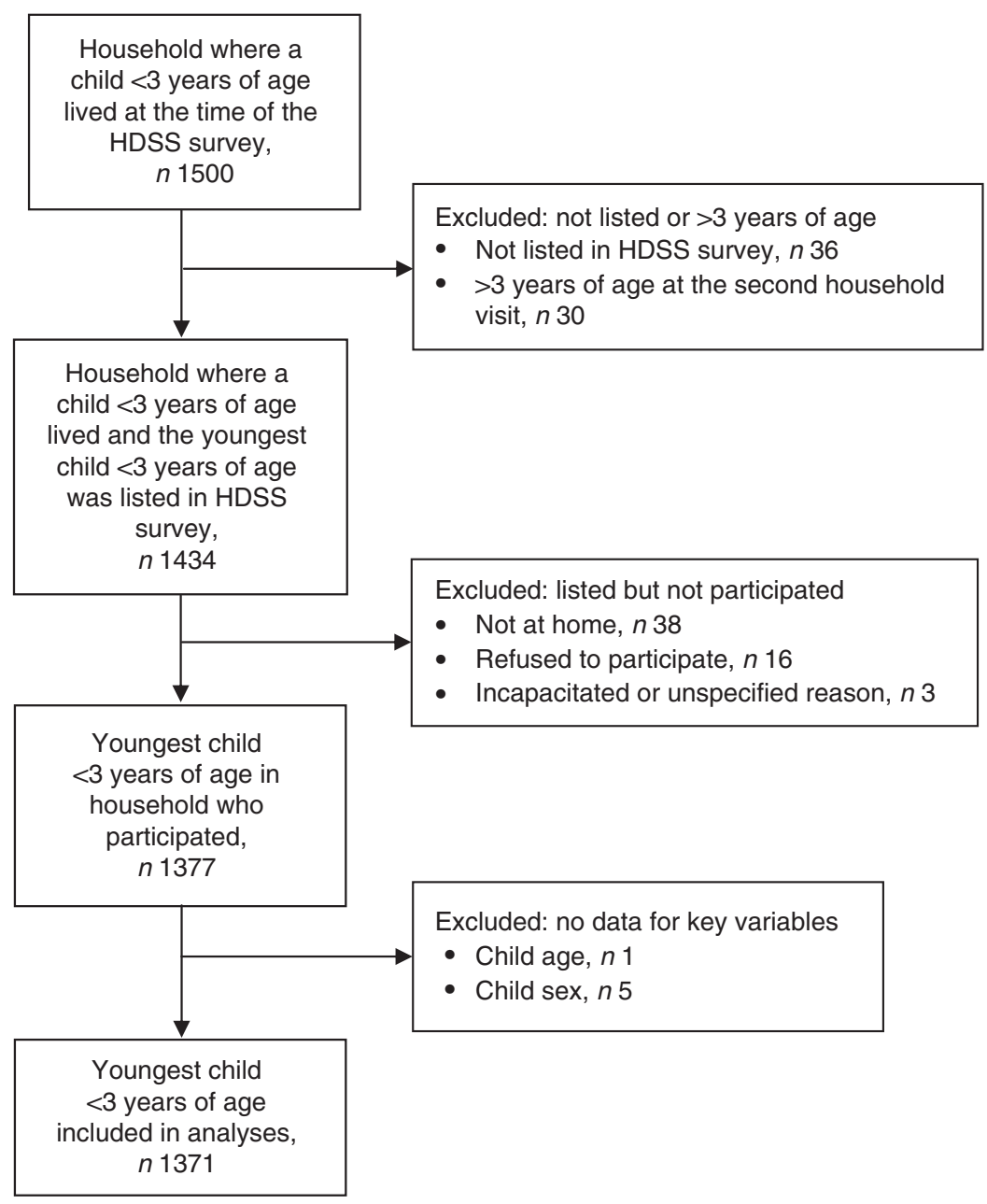

Fig. 1 Flowchart of participation in the infant and young child feeding and nutrition study in Los Cuatro Santos, Nicaragua, 2009 (HDDS, Health and Demographic Surveillance System)

of foods to give to their children. Moreover, almost $63 \%$ of the women could decide to a large extent or on their own when and where they could take their sick children for treatment (results not shown). The mean score for women's social support was $39 \cdot 2$ (SD 7.50; range 19-72). About $20 \%$ of the women reported they had no friends and/or relatives and more than $40 \%$ said they hardly had someone who cared about them (results not shown). There was a small negative correlation between women's autonomy and social support (Pearson correlation $=-0 \cdot 1, P<0 \cdot 01$; results not shown).

\section{Associations between women's autonomy/social support and infant/young child feeding practices}

Descriptive statistics of infant and young child feeding practices according to women's autonomy and social support are presented in Table 3. Compared with women in the highest autonomy tertile, women in the lowest tertile had more appropriate breast-feeding practices, i.e. the odds for not exclusive breast-feeding (adjusted odds ratio $\left(\mathrm{OR}_{\mathrm{adj}}\right)=$ 0.24; $95 \%$ CI 0.08, 0.71) and not continued breast-feeding $\left(\mathrm{OR}_{\mathrm{adj}}=0 \cdot 24 ; 95 \% \mathrm{CI} 0 \cdot 07,0 \cdot 81\right)$ were lower among these women (Table 4). Women in the middle tertile of autonomy had generally better complementary feeding practices, i.e. compared with the women in the highest tertile, the odds for not meeting minimum meal frequency $\left(\mathrm{OR}_{\mathrm{adj}}=0 \cdot 68 ; 95 \% \mathrm{CI}\right.$ $0.50,0 \cdot 94)$, dietary diversity $\left(\mathrm{OR}_{\mathrm{adj}}=0.69 ; 95 \% \mathrm{CI} 0 \cdot 48,0.98\right)$ and acceptable diet $\left(\mathrm{OR}_{\mathrm{adj}}=0.63 ; 95 \% \mathrm{CI} 0 \cdot 46,0 \cdot 85\right)$ were lower among the children of women in this group. However, children of women in the middle tertile of autonomy also had higher odds of consuming HP snacks and/or SSB. The results remained significant after adjustment for potential confounders $\left(\mathrm{OR}_{\mathrm{adj}}=1.45\right.$; $95 \%$ CI 1.02, 2.06; Table 4).

Children of women with lowest social support were more likely to consume HP snacks and/or SSB $\left(\mathrm{OR}_{\mathrm{adj}}=1 \cdot 56\right.$; $95 \%$ CI 1·10, 2·23), but also had marginally significant higher odds of meeting dietary diversity (Table 4). No other associations were found between women's social support and infant and young child feeding practices in the adjusted models.

\section{Associations between women's autonomy/social support and child nutritional status}

Descriptive statistics of child nutritional status by women's autonomy and social support are presented in Table 5. 
Table 1 Characteristics of households, women and children aged 0-35 months in Los Cuatro Santos, Nicaragua, 2009

\begin{tabular}{|c|c|c|}
\hline & $n$ & $\%$ \\
\hline \multicolumn{3}{|l|}{ Household characteristics } \\
\hline \multicolumn{3}{|l|}{ Housing quality } \\
\hline Tap water & 305 & $22 \cdot 2$ \\
\hline Latrine/toilet & 1037 & $75 \cdot 7$ \\
\hline Soil/earth floor & 933 & 68.1 \\
\hline Wall of adobe/brick/wood & 1343 & 98.0 \\
\hline Electricity & 1076 & 78.5 \\
\hline Home garden in use & 108 & 8.0 \\
\hline \multicolumn{3}{|l|}{ Women's characteristics } \\
\hline \multicolumn{3}{|l|}{ Age (years) } \\
\hline$<20$ & 175 & $12 \cdot 8$ \\
\hline $20-29$ & 664 & 48.6 \\
\hline$\geq 30$ & 527 & 38.6 \\
\hline \multicolumn{3}{|l|}{ Education } \\
\hline$<5$ years & 488 & 35.8 \\
\hline $5-9$ years & 588 & 43.1 \\
\hline$>9$ years & 288 & 21.1 \\
\hline \multicolumn{3}{|l|}{ Marital status } \\
\hline Single/divorced/widow & 176 & $12 \cdot 8$ \\
\hline Married/with partner & 1195 & $87 \cdot 2$ \\
\hline \multicolumn{3}{|l|}{ Occupation } \\
\hline Office worker, health worker, teacher & 73 & 5.4 \\
\hline Housewife & 1221 & 89.7 \\
\hline Other & 67 & 4.9 \\
\hline \multicolumn{3}{|l|}{ Child characteristics } \\
\hline \multicolumn{3}{|l|}{ Age (months) } \\
\hline $0-5$ & 231 & $16 \cdot 8$ \\
\hline $6-11$ & 250 & $18 \cdot 2$ \\
\hline $12-23$ & 441 & $32 \cdot 2$ \\
\hline 24-35 & 449 & $32 \cdot 7$ \\
\hline \multicolumn{3}{|l|}{ Sex } \\
\hline Male & 668 & 48.7 \\
\hline \multicolumn{3}{|l|}{ Nutritional status } \\
\hline Stunted & 271 & $20 \cdot 2$ \\
\hline Wasted & 56 & 4.2 \\
\hline Underweight & 75 & 5.5 \\
\hline Overweight & 115 & 8.6 \\
\hline
\end{tabular}

Definitions: stunted, height-for-age $Z$-score $<-2$; wasted, weight-for-height $Z$-score $<-2$; underweight, weight-for-age $Z$-score $<-2$; overweight, BMI-for-age $Z$-score $>2$.

HAZ and WAZ were significantly higher among the older children of women with highest autonomy in the unadjusted models (Table 6). After adjustment for potential confounders, we did not find any significant associations between women's autonomy and child nutritional status in either of the age categories.

With regard to social support, adjusted analyses showed that children aged 6-35 months of women in the lowest social support tertile had significantly higher HAZ $(\beta=0 \cdot 26$; 95\% CI 0.05, 0.48; Table 6) and lower odds $\left(\mathrm{OR}_{\mathrm{adj}}=0.63\right.$; $95 \%$ CI $0.42,0.93)$ of stunting ( $\mathrm{HAZ}<-2)$ compared with women in the highest social support tertile (results not shown).

\section{Discussion}

In the present study, children of women with lowest autonomy were more likely to be exclusively breast-fed and continue to be breast-fed at 1 year of age. Children of women from the middle tertile of autonomy had better complementary feeding practices, but were also more likely to consume HP snacks and SSB. Children of women with the lowest level of social support had greater odds of HP snacks and SSB consumption, but they also had higher HAZ.

We found that children of women with lowest autonomy were more likely to be exclusively breast-fed and continue to be breast-fed after 1 year of age. This finding is similar to that of a study conducted by Smith et al., where an inverse association between women's autonomy and duration of breast-feeding was reported across subSaharan Africa, South Asia and Latin America ${ }^{(15)}$. In Los Cuatro Santos, low autonomy may prevent women from purchasing commercial baby food products; it might also imply the influence of older relatives and relations who may have traditional views regarding breast-feeding practices. Further, women with lower autonomy may exclusively breast-feed and/or continue breast-feeding as they might be restricted in their mobility and thus stay 
Table 2 Mean and standard deviation of women's score in autonomy and social support in Los Cuatro Santos, Nicaragua, 2009 ( $n$ 1371)

\begin{tabular}{|c|c|c|c|c|c|}
\hline \multicolumn{3}{|c|}{ Questions on autonomy (lowest=1, highest $=5$ ) } & \multicolumn{3}{|c|}{ Questions on social support (lowest $=1$, highest $=5$ ) } \\
\hline Question & Mean & SD & Question & Mean & SD \\
\hline Household purchases for daily needs & 3.84 & 1.00 & How many friends and relatives do you have & $2 \cdot 40$ & 1.08 \\
\hline Make large household purchases & 3.57 & 0.97 & How often do you meet your close friends & 3.95 & 1.45 \\
\hline Buy clothes for yourself & 4.50 & 0.83 & Get visit from friends and relatives & 2.38 & $1 \cdot 10$ \\
\hline Buy toiletries for yourself & 4.65 & 0.72 & Get help with daily chores around home & 2.94 & 1.31 \\
\hline When and in which order make chores & 4.75 & 0.61 & Do you get praise for a good job & $2 \cdot 28$ & 0.98 \\
\hline Whether you should earn money & 3.75 & 0.96 & Have people who care what happens to you & 1.82 & 0.88 \\
\hline Which foods to cook each day & 4.58 & 0.78 & Get love and affection & 1.75 & 0.84 \\
\hline What food to give to children & 4.56 & 0.77 & Chance to talk to someone about problems with daily chores & 3.00 & $1 \cdot 19$ \\
\hline Small purchases for children's daily need & 4.09 & 0.97 & Chance to talk to someone you trust about your personal problems & 2.89 & 1.23 \\
\hline Larger purchases for children's need & 3.74 & 0.94 & Chance to talk about money matters & 2.90 & 1.22 \\
\hline How your children should be disciplined & 3.65 & 0.83 & Get invitations to go out and do things with other people & 2.79 & 1.02 \\
\hline When and where you go when you fall sick & 4.22 & 0.90 & Useful advice about important things in life & 2.34 & $1 \cdot 10$ \\
\hline Whether you should use any method to avoid children & 3.88 & 0.90 & Get help when you are sick in bed & 2.38 & 1.01 \\
\hline When and where you take sick children for treatment & 4.06 & 0.93 & Get help with chores outside your home & 2.52 & 1.09 \\
\hline Accompanied by children visiting friends/relatives & 3.76 & 0.94 & Get help with money in an emergency & 2.80 & 1.37 \\
\hline Accompanied by children visiting friends/relatives including overnight stay & 3.53 & 0.91 & & & \\
\hline When and which friends are visiting you at your house & 4.23 & 0.96 & & & \\
\hline
\end{tabular}

Table 3 Descriptive statistics of infant/young child feeding practices and consumption of HP snacks and/or SSB according to women's autonomy and social support in Los Cuatro Santos, Nicaragua, 2009

\begin{tabular}{|c|c|c|c|c|c|c|c|c|c|c|c|c|c|c|c|c|c|c|c|c|c|c|c|}
\hline \multirow[b]{3}{*}{ Feeding practices } & & & & \multicolumn{9}{|c|}{ Women's level of autonomy } & \multicolumn{10}{|c|}{ Women's level of social support } & \multirow[b]{3}{*}{$P$ value } \\
\hline & \multicolumn{3}{|c|}{ Total } & \multicolumn{3}{|c|}{ Highest } & \multicolumn{3}{|c|}{ Middle } & \multicolumn{3}{|c|}{ Lowest } & \multirow[b]{2}{*}{$P$ value } & \multicolumn{3}{|c|}{ Highest } & \multicolumn{3}{|c|}{ Middle } & \multicolumn{3}{|c|}{ Lowest } & \\
\hline & $n / N$ & $\%$ & $95 \% \mathrm{Cl}$ & $n / N$ & $\%$ & $95 \% \mathrm{Cl}$ & $n / N$ & $\%$ & $95 \% \mathrm{Cl}$ & $n / N$ & $\%$ & $95 \% \mathrm{Cl}$ & & $n / N$ & $\%$ & $95 \% \mathrm{Cl}$ & $n / N$ & $\%$ & $95 \% \mathrm{Cl}$ & $n / N$ & $\%$ & $95 \% \mathrm{Cl}$ & \\
\hline EBF (0-5 months) & $72 / 211$ & $34 \cdot 1$ & $28 \cdot 0,40 \cdot 7$ & $17 / 69$ & $24 \cdot 6$ & $15 \cdot 6,35 \cdot 8$ & $26 / 75$ & 34.7 & $24 \cdot 6,45 \cdot 9$ & $29 / 67$ & $43 \cdot 3$ & $31 \cdot 8,55 \cdot 3$ & 0.07 & $19 / 55$ & 34.5 & $22 \cdot 9,47 \cdot 8$ & $35 / 86$ & $40 \cdot 7$ & $30 \cdot 7,51 \cdot 3$ & $18 / 70$ & $25 \cdot 7$ & $16 \cdot 5,36 \cdot 9$ & 0.14 \\
\hline $\begin{array}{l}\text { Continued BF } \\
\text { (12-15 months) }\end{array}$ & $125 / 161$ & 77.6 & $70 \cdot 7,83 \cdot 6$ & $39 / 57$ & 68.4 & $55 \cdot 6,79.5$ & $38 / 49$ & 77.6 & $64 \cdot 3,87 \cdot 6$ & $48 / 55$ & 87.3 & $76 \cdot 4,94 \cdot 3$ & 0.06 & $46 / 54$ & 85.2 & $73 \cdot 8,92 \cdot 9$ & $49 / 68$ & $72 \cdot 1$ & $60 \cdot 5,81 \cdot 7$ & $30 / 39$ & 76.9 & $61 \cdot 9,88 \cdot 1$ & 0.22 \\
\hline MMF (6-35 months) & $683 / 1138$ & $60 \cdot 0$ & $57 \cdot 2,62 \cdot 8$ & $209 / 360$ & $58 \cdot 1$ & $52 \cdot 9,63 \cdot 1$ & $249 / 385$ & 64.7 & $59 \cdot 8,69 \cdot 3$ & $225 / 393$ & $57 \cdot 3$ & $52 \cdot 3,62 \cdot 1$ & 0.07 & $244 / 398$ & 61.3 & $56 \cdot 4,66 \cdot 0$ & $247 / 420$ & 58.8 & $54 \cdot 0,63 \cdot 4$ & $192 / 320$ & 60.0 & $54 \cdot 6,65 \cdot 3$ & 0.77 \\
\hline MDD (6-35 months) & $772 / 1140$ & 67.7 & $65 \cdot 0,70 \cdot 4$ & $228 / 362$ & 63.0 & $57.9,67.8$ & $290 / 385$ & $75 \cdot 3$ & $70 \cdot 8,79 \cdot 4$ & $254 / 393$ & 64.6 & $59.8,69 \cdot 2$ & $<0.01$ & $247 / 398$ & 62.1 & $57 \cdot 2,66 \cdot 7$ & $288 / 421$ & 68.4 & $63 \cdot 8,72 \cdot 7$ & $237 / 321$ & 73.8 & $68 \cdot 8,78 \cdot 4$ & $<0.01$ \\
\hline MAD (6-35 months) & $459 / 1138$ & 40.3 & $37 \cdot 5,43 \cdot 2$ & $128 / 360$ & 35.6 & $30.7,40 \cdot 6$ & $187 / 385$ & 48.6 & $43 \cdot 6,53 \cdot 6$ & $144 / 393$ & $36 \cdot 6$ & $32 \cdot 0,41 \cdot 5$ & $<0.01$ & $149 / 398$ & 37.4 & $32 \cdot 8,42 \cdot 3$ & $171 / 420$ & 40.7 & $36 \cdot 1,45 \cdot 5$ & $139 / 320$ & 43.4 & $38.1,48.9$ & 0.26 \\
\hline $\begin{array}{l}\text { Consumption of HP } \\
\text { snacks and SSB } \\
\text { (6-35 months) }\end{array}$ & $783 / 1140$ & 68.7 & $66 \cdot 0,71 \cdot 3$ & $238 / 362$ & 65.7 & $60.7,70.5$ & $297 / 385$ & 77.1 & $72 \cdot 8,81 \cdot 1$ & $248 / 393$ & 63.1 & $58.2,67.8$ & $<0.01$ & $250 / 398$ & 62.8 & $58 \cdot 0,67.5$ & $291 / 421$ & 69.1 & $64 \cdot 6,73 \cdot 4$ & $242 / 321$ & 75.4 & $70.4,79.9$ & $<0.01$ \\
\hline
\end{tabular}

HP, highly processed, SSB, sugar-sweetened beverages; $N$, total number of children in the age group; EBF, exclusive breast-feeding; BF, breast-feeding; MMF, minimum meal frequency; MDD, minimum dietary diversity; MAD, minimum acceptable diet. 
Table 4 Odds of inappropriate feeding practices among children 0-35 months of age according to women's autonomy and social support in Los Cuatro Santos, Nicaragua, 2009

\begin{tabular}{|c|c|c|c|c|c|c|c|c|c|c|c|c|c|}
\hline \multirow[b]{3}{*}{ Inappropriate Infant/young child feeding practices } & \multirow[b]{3}{*}{ Model } & \multicolumn{6}{|c|}{ Women's level of autonomy } & \multicolumn{6}{|c|}{ Women's level of social support } \\
\hline & & \multicolumn{2}{|c|}{ Highest } & \multicolumn{2}{|c|}{ Middle } & \multicolumn{2}{|c|}{ Lowest } & \multicolumn{2}{|c|}{ Highest } & \multicolumn{2}{|c|}{ Middle } & \multicolumn{2}{|c|}{ Lowest } \\
\hline & & OR & $95 \% \mathrm{Cl}$ & OR & $95 \% \mathrm{Cl}$ & OR & $95 \% \mathrm{Cl}$ & OR & $95 \% \mathrm{Cl}$ & OR & $95 \% \mathrm{Cl}$ & OR & $95 \% \mathrm{Cl}$ \\
\hline Not continued BF (12-15 months; $n$ 164) & $\begin{array}{l}\text { Unadjusted } \\
\text { Model I } \\
\text { Model II }\end{array}$ & $\begin{array}{l}1.00 \\
1.00 \\
1.00\end{array}$ & $\begin{array}{l}\text { Ref. } \\
\text { Ref. } \\
\text { Ref. }\end{array}$ & $\begin{array}{l}0.63 \\
0.70 \\
0.71\end{array}$ & $\begin{array}{l}0.26,1.50 \\
0.25,1.95 \\
0.25,2.02\end{array}$ & $\begin{array}{l}0.32^{*} \\
0.23^{*} \\
0.24^{*}\end{array}$ & $\begin{array}{l}0.12,0.83 \\
0.07,0.78 \\
0.07,0.81\end{array}$ & $\begin{array}{l}1.00 \\
1.00 \\
1.00\end{array}$ & $\begin{array}{l}\text { Ref. } \\
\text { Ref. } \\
\text { Ref. }\end{array}$ & $\begin{array}{l}2 \cdot 23 \\
2 \cdot 27 \\
2 \cdot 64\end{array}$ & $\begin{array}{l}0.89,5.59 \\
0.93,7.93 \\
0.91,7.65\end{array}$ & $\begin{array}{l}1.72 \\
2.12 \\
1.79\end{array}$ & $\begin{array}{l}0.60,4.97 \\
0.67,6.69 \\
0.55,5.80\end{array}$ \\
\hline No MDD (6-35 months; $n$ 1140) & $\begin{array}{l}\text { Unadjusted } \\
\text { Model I } \\
\text { Model II }\end{array}$ & $\begin{array}{l}1.00 \\
1.00 \\
1.00\end{array}$ & $\begin{array}{l}\text { Ref. } \\
\text { Ref. } \\
\text { Ref. }\end{array}$ & $\begin{array}{l}0.56^{* *} \\
0.70^{*} \\
0.69^{*}\end{array}$ & $\begin{array}{l}0.46,0.76 \\
0.49,0.99 \\
0.48,0.98\end{array}$ & $\begin{array}{l}0.93 \\
1.11 \\
1.06\end{array}$ & $\begin{array}{l}0.69,1.25 \\
0.78,1.59 \\
0.74,1.52\end{array}$ & $\begin{array}{l}1.00 \\
1.00 \\
1.00\end{array}$ & $\begin{array}{l}\text { Ref. } \\
\text { Ref. } \\
\text { Ref. }\end{array}$ & $\begin{array}{l}0.76 \\
0.94 \\
0.92\end{array}$ & $\begin{array}{l}0.57,1.01 \\
0.68,1.30 \\
0.66,1.27\end{array}$ & $\begin{array}{l}0.58^{\star \star} \\
0.72 \\
0.73\end{array}$ & $\begin{array}{l}0.42,0.80 \\
0.51,1.01 \\
0.51,1.03\end{array}$ \\
\hline No MAD (6-35 months; $n$ 1140) & $\begin{array}{l}\text { Unadjusted } \\
\text { Model I } \\
\text { Model II }\end{array}$ & $\begin{array}{l}1.00 \\
1.00 \\
1.00\end{array}$ & $\begin{array}{l}\text { Ref. } \\
\text { Ref. } \\
\text { Ref. }\end{array}$ & $\begin{array}{l}0.58^{\star \star} \\
0.63^{\star \star} \\
0.63^{\star \star}\end{array}$ & $\begin{array}{l}0.44,0.78 \\
0.46,0.86 \\
0.46,0.85\end{array}$ & $\begin{array}{l}0.95 \\
0.94 \\
0.91\end{array}$ & $\begin{array}{l}0.71,1.28 \\
0.67,1.31 \\
0.65,1.28\end{array}$ & $\begin{array}{l}1.00 \\
1.00 \\
1.00\end{array}$ & $\begin{array}{l}\text { Ref. } \\
\text { Ref. } \\
\text { Ref. }\end{array}$ & $\begin{array}{l}0.87 \\
1.00 \\
0.97\end{array}$ & $\begin{array}{l}0.66,1.15 \\
0.75,1.34 \\
0.72,1.31\end{array}$ & $\begin{array}{l}0.78 \\
0.82 \\
0.81\end{array}$ & $\begin{array}{l}0.58,1.05 \\
0.60,1.12 \\
0.59,1.12\end{array}$ \\
\hline
\end{tabular}

EBF, exclusive breast-feeding; BF, breast-feeding; MMF, minimum meal frequency; MDD, minimum dietary diversity; MAD, minimum acceptable diet; HP, highly processed; SSB, sugar-sweetened beverages; Ref., Referent category.
${ }_{*} P<0.05, * * P<0.01$

†Adjusted for municipality, housing quality, food insecurity, women's education, women's age (years) and child age (months).

ҒAdjusted as in Model I adding women's level of social supportautonomy using multivariate logistic regression. 
more at home and have more opportunities to breast-feed. Children of women in the middle tertile of autonomy had the best complementary feeding practices. A potential explanation might be that while low autonomy reduces women's access to and control over resources in the household, the highest scores in autonomy might imply a lower level of partner support and thus more responsibility for women, which could reduce their caregiving capacity. Furthermore, women in the middle tertile of autonomy may be deciding jointly with their partners. This might reflect good relations and potentially better communication between partners which might have resulted in better child complementary feeding practices.

The difference in terms of better breast-feeding practices among the women within the lowest tertile of autonomy as compared with better complementary feeding among women within the middle tertile might also reflect their access over the family's economic resources. That is, while women in the lowest autonomy tertile chose to breast-feed because of not having enough money to buy commercial baby food products, higher level of women's autonomy might increase their economic freedom which may translate into better complementary feeding after 6 months of age when more external resources rather than breast milk are necessary to meet children's dietary needs.

We did not find women's autonomy to be significantly associated with child nutritional status. This finding is consistent with a study conducted in Kenya, which found no significant association between women's autonomy and nutritional status in children younger than 3 years of age. The authors hypothesized that receiving a significant portion of nutrition from breast milk might buffer women's limited control over household resources ${ }^{(14)}$. By contrast, greater women's autonomy was associated with better nutritional status in children under 3 years in Jordan ${ }^{(13)}$ and India ${ }^{(11,12)}$. The weaker influence of women's decision making on child nutritional status in Latin American countries compared with South-East Asia and sub-Saharan Africa has been reported in previous studies ${ }^{(15)}$. Although the results were not significant, the direction of association showed that higher women's autonomy was related with better nutritional status in children older than 6 months in our study. In general, the higher status of women in Latin America ${ }^{(15)}$ and a lower prevalence of malnutrition in our sample might have limited us from finding significant associations between women's autonomy and child nutritional status.

No significant associations were found between women's social support and infant/young child feeding practices. However, contrary to what was expected, women in the lowest tertile of social support had infants with the highest HAZ and also the lowest occurrence of stunting. Similarly to this finding, a study that included 1-year-old children from Peru, Ethiopia, Vietnam and India reported that while support from one individual was associated with better WHZ among the children, women's support from two or 
Table 6 Association of child nutritional status with women's autonomy and social support in children aged 0-5 and 6-35 months in Los Cuatro Santos, Nicaragua, 2009

\begin{tabular}{|c|c|c|c|c|c|c|c|c|c|c|c|c|c|c|}
\hline \multirow[b]{3}{*}{ Nutritional status } & \multirow[b]{3}{*}{ Age group } & \multirow[b]{3}{*}{ Model } & \multicolumn{6}{|c|}{ Women's level of autonomy } & \multicolumn{6}{|c|}{ Women's level of social support } \\
\hline & & & Highest & \multicolumn{2}{|c|}{ Middle } & \multicolumn{2}{|c|}{ Lowest } & \multirow[b]{2}{*}{$R^{2}$} & Highest & \multicolumn{2}{|c|}{ Middle } & \multicolumn{2}{|c|}{ Lowest } & \multirow[b]{2}{*}{$R^{2}$} \\
\hline & & & $\beta \quad 95 \% \mathrm{Cl}$ & $\beta$ & $95 \% \mathrm{Cl}$ & $\beta$ & $95 \% \mathrm{Cl}$ & & $\beta \quad 95 \% \mathrm{Cl}$ & $\beta$ & $95 \% \mathrm{Cl}$ & $\beta$ & $95 \% \mathrm{Cl}$ & \\
\hline HAZ & $\begin{array}{l}<6 \text { months }(n 231) \\
\geq 6 \text { months }(n 1140)\end{array}$ & $\begin{array}{l}\text { Unadjusted } \\
\text { Model I† } \\
\text { Model II } \\
\text { Unadjusted } \\
\text { Model I } \\
\text { Model II }\end{array}$ & $\begin{array}{l}\text { Ref. } \\
\text { Ref. } \\
\text { Ref. } \\
\text { Ref. } \\
\text { Ref. } \\
\text { Ref. }\end{array}$ & $\begin{array}{l}0.27 \\
0.25 \\
0.16 \\
-0.22^{*} \\
-0.17 \\
-0.17\end{array}$ & $\begin{array}{l}-0.22,0.77 \\
-0.27,0.77 \\
-0.37,0.69 \\
-0.44,-0.00 \\
-0.39,0.04 \\
-0.38,0.04\end{array}$ & $\begin{array}{l}0.20 \\
0.32 \\
0.26 \\
-0.30^{\star} \\
-0.11 \\
-0.07\end{array}$ & $\begin{array}{l}-0.32,0.73 \\
-0.30,0.95 \\
-0.38,0.89 \\
-0.52,-0.09 \\
-0.33,0.12 \\
-0.30,0.16\end{array}$ & $\begin{array}{l}0.006 \\
0.096 \\
0.109 \\
0.007 \\
0.125 \\
0.130\end{array}$ & $\begin{array}{l}\text { Ref. } \\
\text { Ref. } \\
\text { Ref. } \\
\text { Ref. } \\
\text { Ref. } \\
\text { Ref. }\end{array}$ & $\begin{array}{r}-0.37 \\
-0.50 \\
-0.46 \\
0.06 \\
0.03 \\
0.02\end{array}$ & $\begin{array}{l}-0.91,0.17 \\
-1.05,0.05 \\
-1.03,0.10 \\
-0.14,0.27 \\
-0.17,0.23 \\
-0.18,0.22\end{array}$ & $\begin{array}{r}-0.02 \\
-0.15 \\
-0.14 \\
0.24^{\star} \\
0.27^{\star} \\
0.26^{\star}\end{array}$ & $\begin{array}{r}-0.56,0.53 \\
-0.71,0.40 \\
-0.70,0.42 \\
0.02,0.47 \\
0.06,0.48 \\
0.05,0.48\end{array}$ & $\begin{array}{l}0.013 \\
0.106 \\
0.109 \\
0.004 \\
0.128 \\
0.130\end{array}$ \\
\hline WHZ & $\begin{array}{l}<6 \text { months }(n 231) \\
\geq 6 \text { months }(n 1140)\end{array}$ & $\begin{array}{l}\text { Unadjusted } \\
\text { Model I } \\
\text { Model II } \\
\text { Unadjusted } \\
\text { Model I } \\
\text { Model II }\end{array}$ & $\begin{array}{l}\text { Ref. } \\
\text { Ref. } \\
\text { Ref. } \\
\text { Ref. } \\
\text { Ref. } \\
\text { Ref. }\end{array}$ & $\begin{array}{l}-0.37 \\
-0.29 \\
-0.19 \\
-0.09 \\
-0.04 \\
-0.04\end{array}$ & $\begin{array}{l}-0.91,0.16 \\
-0.85,0.27 \\
-0.75,0.38 \\
-0.26,0.08 \\
-0.21,0.14 \\
-0.21,0.14\end{array}$ & $\begin{array}{l}-0.10 \\
-0.08 \\
-0.01 \\
-0.14 \\
-0.06 \\
-0.07\end{array}$ & $\begin{array}{l}-0.66,0.46 \\
-0.74,0.58 \\
-0.67,0.65 \\
-0.30,0.03 \\
-0.24,0.13 \\
-0.26,0.12\end{array}$ & $\begin{array}{l}0.009 \\
0.048 \\
0.068 \\
0.002 \\
0.035 \\
0.035\end{array}$ & $\begin{array}{l}\text { Ref. } \\
\text { Ref. } \\
\text { Ref. } \\
\text { Ref. } \\
\text { Ref. } \\
\text { Ref. }\end{array}$ & $\begin{array}{l}0.45 \\
0.64^{*} \\
0.60 \\
-0.06 \\
-0.02 \\
-0.02\end{array}$ & $\begin{array}{r}-0.12,1.03 \\
0.04,1.24 \\
-0.02,1.21 \\
-0.22,0.10 \\
-0.18,0.15 \\
-0.19,0.14\end{array}$ & $\begin{array}{r}0.16 \\
0.20 \\
0.16 \\
-0.02 \\
-0.07 \\
-0.08\end{array}$ & $\begin{array}{l}-0.42,0.74 \\
-0.40,0.79 \\
-0.44,0.77 \\
-0.19,0.16 \\
-0.25,0.10 \\
-0.26,0.10\end{array}$ & $\begin{array}{l}0.012 \\
0.065 \\
0.068 \\
0.000 \\
0.035 \\
0.035\end{array}$ \\
\hline WAZ & $\geq 6$ months ( $n$ 1140) & $\begin{array}{l}\text { Unadjusted } \\
\text { Model I } \\
\text { Model II } \\
\text { Unadjusted } \\
\text { Model I } \\
\text { Model II }\end{array}$ & $\begin{array}{l}\text { Ref. } \\
\text { Ref. } \\
\text { Ref. } \\
\text { Ref. } \\
\text { Ref. } \\
\text { Ref. }\end{array}$ & $\begin{array}{l}0.14 \\
0.21 \\
0.14 \\
-0.22^{\star} \\
-0.15 \\
-0.15\end{array}$ & $\begin{array}{l}-0.27,0.54 \\
-0.21,0.63 \\
-0.28,0.57 \\
-0.38,-0.06 \\
-0.31,0.02 \\
-0.32,0.01\end{array}$ & $\begin{array}{l}0.34 \\
0.39 \\
0.37 \\
-0.29^{\star \star} \\
-0.11 \\
-0.11\end{array}$ & $\begin{array}{l}-0.08,0.77 \\
-0.12,0.90 \\
-0.14,0.88 \\
-0.45,-0.12 \\
-0.29,0.06 \\
-0.29,0.07\end{array}$ & $\begin{array}{l}0.011 \\
0.071 \\
0.079 \\
0.011 \\
0.081 \\
0.083\end{array}$ & $\begin{array}{l}\text { Ref. } \\
\text { Ref. } \\
\text { Ref. } \\
\text { Ref. } \\
\text { Ref. } \\
\text { Ref. }\end{array}$ & $\begin{array}{l}-0.31 \\
-0.34 \\
-0.32 \\
-0.04 \\
-0.03 \\
-0.05\end{array}$ & $\begin{array}{l}-0.75,0.12 \\
-0.80,0.11 \\
-0.79,0.15 \\
-0.19,0.12 \\
-0.19,0.12 \\
-0.20,0.11\end{array}$ & $\begin{array}{r}-0.15 \\
-0.23 \\
-0.23 \\
0.10 \\
0.06 \\
0.05\end{array}$ & $\begin{array}{l}-0.59,0.28 \\
-0.68,0.23 \\
-0.69,0.23 \\
-0.07,0.27 \\
-0.10,0.23 \\
-0.12,0.22\end{array}$ & $\begin{array}{l}0.009 \\
0.070 \\
0.079 \\
0.002 \\
0.080 \\
0.083\end{array}$ \\
\hline BAZ & $\geq 6$ months ( $n 1140)$ & $\begin{array}{l}\text { Unadjusted } \\
\text { Model I } \\
\text { Model II } \\
\text { Unadjusted } \\
\text { Model I } \\
\text { Model II }\end{array}$ & $\begin{array}{l}\text { Ref. } \\
\text { Ref. } \\
\text { Ref. } \\
\text { Ref. } \\
\text { Ref. } \\
\text { Ref. }\end{array}$ & $\begin{array}{r}-0.23 \\
-0.14 \\
-0.07 \\
-0.04 \\
0.01 \\
0.00\end{array}$ & $\begin{array}{l}-0.72,0.25 \\
-0.64,0.36 \\
-0.58,0.44 \\
-0.21,0.14 \\
-0.17,0.19 \\
-0.18,0.18\end{array}$ & $\begin{array}{r}0.04 \\
0.06 \\
0.11 \\
-0.10 \\
-0.05 \\
0.07\end{array}$ & $\begin{array}{l}-0.47,0.54 \\
-0.53,0.66 \\
-0.49,0.70 \\
-0.27,0.08 \\
-0.24,0.14 \\
-0.26,0.12\end{array}$ & $\begin{array}{l}0.006 \\
0.048 \\
0.059 \\
0.001 \\
0.043 \\
0.044\end{array}$ & $\begin{array}{l}\text { Ref. } \\
\text { Ref. } \\
\text { Ref. } \\
\text { Ref. } \\
\text { Ref. } \\
\text { Ref. }\end{array}$ & $\begin{array}{r}0.27 \\
0.40 \\
0.38 \\
-0.09 \\
-0.04 \\
-0.04\end{array}$ & $\begin{array}{l}-0.25,0.80 \\
-0.14,0.95 \\
-0.17,0.94 \\
-0.25,0.08 \\
-0.21,0.13 \\
-0.22,0.13\end{array}$ & $\begin{array}{r}0.11 \\
0.12 \\
0.10 \\
-0.05 \\
-0.12 \\
-0.13\end{array}$ & $\begin{array}{l}-0.41,0.64 \\
-0.42,0.66 \\
-0.45,0.64 \\
-0.23,0.13 \\
-0.30,0.06 \\
-0.31,0.06\end{array}$ & $\begin{array}{l}0.005 \\
0.057 \\
0.059 \\
0.001 \\
0.044 \\
0.044\end{array}$ \\
\hline
\end{tabular}

HAZ, height-for-age Z-score; WHZ, weight-for-height Z-score; WAZ, weight-for-age Z-score; BAZ, BMI-for-age Z-score; Ref., Referent category.

${ }^{\star} P<0.05,{ }^{\star \star} P<0.01$.

†Adjusted for municipality, housing quality, food insecurity, women's education, women's age (years) and child age (months).

$\ddagger$ Adjusted as in Model I adding women's level of social support/autonomy using the general linear model. 
more individuals was associated with a slight reduction in their children's WHZ except for those in non-poor households $^{(37)}$. A large social support may not always be beneficial as it may also reflect the number of people whom an individual is obliged to care for and not only the number of people who care about the individual. Therefore a higher social support score might imply higher amounts of stress and responsibilities, which can negatively affect the quality and quantity of women's caregiving practices. Consistent with this explanation, an earlier study in Nicaragua showed increased mental distress among families with higher levels of social support ${ }^{(38)}$. Moreover, it has been shown that the presence of the immediate kin at the time of childbearing, although beneficial, can also entail stress and conflict due to interpersonal tensions and conflicting interests ${ }^{(39)}$. The added responsibilities and emotional toll that may come with maintaining social networks may outweigh the actual support that such networks supply to women, thus diminishing their caring capacity and ultimately affecting their children's nutritional status. Another alternative explanation for the association found between women's social support and children's nutritional status is the possibility of reverse causality, whereby women might seek more social support in order to get help when their children do not grow properly.

The associations between the explanatory factors and child feeding and nutritional status did not follow a consistent pattern in our study. For instance, while children of women in the middle tertile of autonomy had better complementary feeding practices, their children did not have better nutritional status. Similarly, the lowest tertile of women's social support was associated with better child nutritional status but not with better infant and young child feeding practices. Given that child growth is a result not only of feeding practices but also of other factors in the children's social and physical environment, this may not be surprising.

Some strengths of our study are the high participation (92\%) of the eligible children and the use of a validated tool for assessment of women's social support, as well as including child-related items in the women's autonomy questionnaire. There are also some limitations such as the cross-sectional nature of the study which will not allow causal inference to be made and reliance on women's responses to a $24 \mathrm{~h}$ FFQ that may not reflect their usual feeding practices. Further, despite adjustment for important potential confounders, the possibility of limitations in assessment of the confounders exists and thus residual confounding cannot be ruled out.

In this rural setting, lower levels of both women's autonomy and social support were independently associated with favourable feeding practices and better nutrition such as more exclusive breast-feeding, better complementary diet and less stunting. However, the significance of these associations should be interpreted with caution as autonomy and social support may reflect broader social and economic structures of importance for child feeding practices and nutrition rather than indicate a causal relationship.

\section{Acknowledgements}

Acknowledgements: The authors are grateful to the study team who collaborated throughout the research process. They also thank the women and children who participated in the study. Financial support: Financial support for the study was provided by the Swedish International Development Cooperation Agency (Sida) and the International Maternal and Child Health Unit, Department of Women's and Children's Health, Uppsala University. The funders had no role in the design, analysis or writing of this article. Conflict of interest: None. Authorship: S.Z. analysed and interpreted the data and drafted the manuscript. E.-C.E. conceived and designed the study, supervised the analyses, interpreted the data and revised the manuscript. M.C. contributed in acquisition of the data, interpretation of the analyses and revising the manuscript. L.-Å.P. contributed in interpretation of the analyses and revising the manuscript. E.Z.B. contributed in the design of the study, was responsible for data collection, contributed in interpretation of the analyses and revising the manuscript. A.H. contributed in interpretation of the analyses and revising the manuscript. All co-authors read and approved the final draft. Ethics of human subject participation: The study was conducted according to the guidelines laid down in the Declaration of Helsinki and all procedures involving human subjects/patients were approved by the Biomedical Research Ethics Committee at the University of León in Nicaragua. Verbal informed consent was obtained from all subjects/patients. Verbal consent was witnessed and formally recorded.

\section{References}

1. Liu L, Johnson HL, Cousens S et al. (2012) Global, regional, and national causes of child mortality: an updated systematic analysis for 2010 with time trends since 2000. Lancet 379, 2151-2161.

2. Engle PL, Menon P \& Haddad L (1999) Care and nutrition: concepts and measurement. World Dev 27, 1309-1337.

3. Fantahun M, Berhane Y, Wall S et al. (2007) Women's involvement in household decision-making and strengthening social capital - crucial factors for child survival in Ethiopia. Acta Paediatr 96, 582-589.

4. Hossain MB, Phillips JF \& Pence B (2007) The effect of women's status on infant and child mortality in four rural areas of Bangladesh. J Biosoc Sci 39, 355-366.

5. Antai D (2012) Gender inequities, relationship power, and childhood immunization uptake in Nigeria: a population-based cross-sectional study. Int J Infect Dis 16, e136-e145.

6. Mashal T, Takano T, Nakamura K et al. (2008) Factors associated with the health and nutritional status of children under 5 years of age in Afghanistan: family behaviour related to women and past experience of war-related hardships. BMC Public Health 8, 301.

7. Esterik PV (1995) Factors influencing care: care, caregiving, and caregivers. Food Nutr Bull 16, 378-388.

8. Adams AM, Madhavan S \& Simon D (2002) Women's social networks and child survival in Mali. Soc Sci Med 54, $165-178$. 
9. Harpham T, De Silva MJ \& Tuan T (2006) Maternal social capital and child health in Vietnam. J Epidemiol Community Health 60, 865-871.

10. Kana'Iaupuni SM, Donato KM, Thompson-Colon $\mathrm{T}$ et al. (2005) Counting on kin: social networks, social support, and child health status. Soc Forces 83, 1137-1164.

11. Shroff M, Griffiths P, Adair L et al. (2009) Maternal autonomy is inversely related to child stunting in Andhra Pradesh, India. Matern Child Nutr 5, 64-74.

12. Shroff MR, Griffiths PL, Suchindran C et al. (2011) Does maternal autonomy influence feeding practices and infant growth in rural India? Soc Sci Med 73, 447-455.

13. Doan RM \& Bisharat L (1990) Female autonomy and child nutritional status: the extended-family residential unit in Amman, Jordan. Soc Sci Med 31, 783-789.

14. Brunson EK, Shell-Duncan B \& Steele M (2009) Women's autonomy and its relationship to children's nutrition among the Rendille of northern Kenya. Am J Hum Biol 21, 55-64.

15. Smith LC, Ramakrishnan U \& Ndiaye A (2003) The Importance of Women's Status for Child Nutrition in Developing Countries. Research Report no. 133. Washington, DC: International Food Policy Research Institute.

16. Surkan PJ, Ryan LM, Carvalho Vieira LM et al. (2007) Maternal social and pyschological conditions and physical growth in low-income children in Piaui, Northeast Brazil. Soc Sci Med 64, 375-388.

17. de BL Carvalhaes MA, D'Aquino Benicio MH \& Barros AJ (2005) Social support and infant malnutrition: a case-control study in an urban area of Southeastern Brazil. Br J Nutr $\mathbf{9 4}$, 383-389.

18. UNICEF (2006) The State of the World's Children 2007. Women and Children: The Double Dividend of Gender Equality. New York: UNICEF.

19. World Bank (2013) Nicaragua Overview. http://www. worldbank.org/en/country/nicaragua/overview (accessed October 2012).

20. UNICEF (2013) Nicaragua Country programme document 2013-2017. http://www.unicef.org/about/execboard/files/2012PL31_Nicaragua_CPD-final_approved-English.pdf (accessed September 2013).

21. Instituto Nacional de Información y Desarrollo/Ministerio de Salud (2013) Nicaragua Demographic and Health Survey 2011/ 12 - Preliminary Report. http://www.inide.gob.ni/endesa/ Endesa11_12/HTML/preliminar.html\#2 (accessed March 2013).

22. UNICEF (2012) Country Office Portal. Annual Report 2011 for Nicaragua, TACRO. http://www.unicef.org/about/annualreport/ files/Nicaragua_COAR_2011.pdf (accessed October 2013).

23. World Health Organization (2011) Noncommunicable Diseases Country Profiles 2011: Nicaragua. http://whqlibdoc. who.int/publications/2011/9789241502283_eng.pdf?ua=1 (accessed August 2013).

24. Contreras M, Zelaya Blandon E, Persson LA et al. (2014) Consumption of highly processed snacks, sugar-sweetened beverages and child feeding practices in a rural area of Nicaragua. Matern Child Nutr (Epublication ahead of print version).
25. DHS Model Questionnaire - Phase 5 (2003-2008) (English) Women's questionnaire (2008). http://dhsprogram.com/ pubs/pdf/DHSQ5/DHS5-Woman\%27s-QRE-22-Aug-2008.pdf (accessed November 2009).

26. Broadhead WE, Gehlbach SH, Degruy FV et al. (1988) The Duke-UNC Functional Social Support Questionnaire measurement of social support in family medicine patients. Med Care 26, 709-723.

27. Alvarado BE, Zunzunegui MV \& Delisle H (2005) Validation of food security and social support scales in an AfroColombian community: application on a prevalence study of nutritional status in children aged 6 to 18 months. Cad Saude Publica 21, 724-736.

28. Pan American Health Organization/World Health Organization (2003) Guiding Principles for Complementary Feeding of the Breastfed Child. Washington, DC: PAHO Division of Health Promotion and Protection, Food and Nutrition Programme.

29. World Health Organization (2008) Indicators for Assessing Infant and Young Child Feeding Practices: Conclusions of a Consensus Meeting Held 6-8 November 2007 in Washington DC, USA, Part 1: Definitions. Geneva: WHO.

30. World Health Organization (2010) Indicators for Assessing Infant and Young Child Feeding Practices: Part II Measurement. Geneva: WHO.

31. World Health Organization, WHO Multicentre Growth Reference Study Group (2006) WHO Child Growth Standards: Length/Height-for-Age, Weight-for-Age, Weight-for-Length, Weight-for-Height and Body Mass Index-for-Age: Methods and Development. Geneva: WHO.

32. World Health Organization (1997) WHO Global Database on Child Growth and Malnutrition. Geneva: WHO.

33. Senarath U, Agho KE, Akram DE et al. (2012) Comparisons of complementary feeding indicators and associated factors in children aged 6-23 months across five South Asian countries. Matern Child Nutr 8, Suppl. 1, S89-S106.

34. David V, Moncada M \& Ordonez F (2004) Private and public determinants of child nutrition in Nicaragua and Western Honduras. Econ Hum Biol 2, 457-488.

35. Coates J, Swindale A \& Bilinsky P (2007) Household Food Insecurity Access Scale (HFIAS) for Measurement of Food Access: Indicator Guide Version 3. Washington, DC: Food and Nutrition Technical Assistance Project, Academy for Educational Development.

36. Dean A, Sullivan K \& Soe M (n.d.) OpenEpi: Open Source Epidemiologic Statistics for Public Health, Version 3.01. http://www.OpenEpi.com (accessed January 2013).

37. De Silva MJ \& Harpham T (2007) Maternal social capital and child nutritional status in four developing countries. Health Place 13, 341-355.

38. Ahearn FL \& Noble JH (2004) Post-civil war adaptation and need in Managua, Nicaragua. J Biosoc Sci 36, 401-415.

39. Cramer JC \& MCDonald KB (1996) Kin support and family stress: two sides to early childbearing and support networks. Hum Organ 55, 160-169. 